\title{
A Novel Approach for Identifying Gas Cavitation in Oil Jet Pumps for Lubrication Systems
}

\author{
Jun Zhang 1 - Peiyong Ma1 - Shuyi Gan ${ }^{1}$ - Xianguo Hu1,* - Shunsen Wang 2 \\ ${ }^{1}$ Hefei University of Technology, School of Mechanical Engineering, China \\ 2 Xi'an Jiaotong University, Institute of Turbomachinery, China
}

Gas cavitation has significant influence on the performance of oil jet pumps for lubrication systems in turbo machinery. This study provides a novel approach for identifying gas cavitation in oil jet pumps. It accounts for the physical process of gas cavitation and its effect on the performance of oil jet pumps. The performance of oil jet pumps, such as their entrainment ability, efficiency, cavitation erosion, vibration, noise, vapour volume fraction, and pressure distribution under variable working conditions, are systematically measured and quantified from experimental and numerical simulation results. Based on the frequency characteristics of the cavitation process and its action mechanism on the performance of oil jet pumps, a novel approach for the identification of gas cavitation is provided. Results show that gas cavitation emerges in a fairly wide working range of oil jet pumps for lubrication systems. Here, the dissolved air content in lubrication oil is 6.3 times larger than that in water, and the oil jet pump is more prone to suffer from cavitation than a water jet pump by $16 \%$. This study promotes a deeper understanding of the mechanics of gas cavitation effects on the fluid machinery in lubrication systems.

Keywords: oil jet pump, lubrication system, identification of gas cavitation, frequency characteristics, gas-liquid two-phase flow

Highlights

- Gas cavitation in oil jet pumps was measured and analysed with experiment and CFD methods.

- A novel approach for the identification of gas cavitation in oil jet pumps was provided.

- Gas cavitation in oil jet pumps emerges at $\sigma=1.68$ and fades at $\sigma=1.31$ with dissolved air content $f_{g}=110 \mathrm{ppm}$ in lubrication oil.

\section{INTRODUCTION}

The oil jet pump is the key component of lubrication systems for turbo machinery. It is used to supply lubrication oil for the bearing and sealing system. However, with the increasing power density of turbo machinery, the working parameters and load of lubrication system increase rapidly. The cavitation problem of oil jet pumps gradually threats the safe operation of turbo machinery [1] and [2].

Cavitation in fluid machinery powered by water has already been extensively studied, such as marine propeller [3], hydrofoils [4] and [5], nozzles [6], washing machines [7], bluff bodies [8], etc. Cavitation in the journal bearings of lubrication systems has also been studied for a long time [9] and [10]. However, cavitation in oil jet pumps for lubrication systems is different from that in hydraulic machinery powered by water or journal bearings.

Fig 1 shows the structure of an oil jet pump. As shown, the oil jet pump entrains with high working pressure, so the pressure in throat decreases and air separates from oil in the low pressure region. The separated air takes up flow passage and the local sound speed is reduced with multiphase flow [11]. Therefore, the particularities of the cavitation problem in oil jet pumps for the lubrication systems of turbo machinery are shown in two aspects. First, the working pressure in the lubrication system commonly is above $2 \mathrm{MPa}$, which brings about extremely high velocity, low pressure, and cavitation regions [6] and [12]. Second, the dissolved air content in lubrication oil is ten times higher than that in water [13] and [14], which promotes air cavitation and noticeably affects the lubrication system [15] and [16]. As a result, studying the cavitation characteristics of oil jet pumps in lubrication systems is of great significance for the safety of turbo machinery.

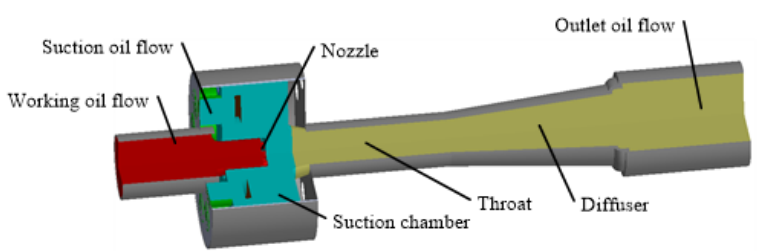

Fig. 1. Structure of oil jet pump

Among various kinds of cavitation in oil jet pumps, gas cavitation is a special kind of cavitation and significantly affects the performance of such pumps. According to Cunningham and Brown's effort in comparing the cavitating flow in oil jet pumps 
with water jet pumps [17], it is found that the oil jet pump is more prone to suffer from cavitation than the water jet pump was. Additionally, Long et al. [18] showed that the choking flow of jet pumps result from the zone of Mach number equals 1 filling the cross section of throat. Therefore, we infer that gas cavitation is able to promote the choking flow of jet pumps; later experimental results had confirmed this. Zhang et al. [19] established an improved cavitation model suitable for the cavitating flow of lubrication oil in a lubrication system based on experimental data. According to this study, the maximum flow capacity of the throat pipe is three times reduced with the increase of non-condensable gas content in lubrication oil. Zou et al. [20] studied the cavitating flow in a non-circular opening spool valve in a hydraulic system. The results show that there is a critical point of non-choking transforming choking flow. However, irrespective of the dissolved air in hydraulic oil, the numerical simulation results are void of this point. The above results support that the large amount of dissolved air in lubrication oil promotes the gas cavitation and choking flow. Compared with that in a water jet pump, its effect on an oil jet pump is significant and cannot be ignored. Therefore, studying the identification of gas cavitation and its effect on the performance of oil jet pumps is especially important.

The difficulty of gas cavitation identification lies in that it is similar to vapour cavitation, such as leading to gas-liquid two-phase flow and occupying the flow passage. Thus, an unconventional method is required for identification. Duke et al. [21] measured the total displacement of the liquid and mass fractions of both dissolved and nucleated gas from $\mathrm{Br}$ and $\mathrm{Kr}$ fluorescence. Then, the volumetric displacement of liquid due to both cavitation and gas precipitation can be separated through the estimation of the local equilibrium-dissolved mass fraction. Zhou et al. [16] presented a novel lumped parameter model of cavitating orifice flow based on the control volume concept. They proposed a procedure of calibrating the unknown model coefficients in the presented mode, and the calibrated model is verified by experiments. Although their study provided an approach for the identification of gas cavitation, it lacks deep analysis of the physical process and mechanism. Therefore, their results are of limited significance for the identification of gas cavitation in fluid machinery powered by lubrication oil.

Some researchers study the influence of gas cavitation on the lubrication or hydraulic system. Kim and Murrenhoff [22] measured the effective bulk modulus of hydraulic oil to improve the simulation accuracy of cavitation, which accounts for the effect of dissolved air separated from oil. Zhou et al. [23] provided a novel approach for the prediction of thermal effects arising from gas cavitation in a hydraulic circuit.

In contrast, the cavitation model was also improved to predict the occurrence of gas cavitation. The cavitation models proposed by Kunz et al. [24] and Sauer [25] scarcely account for the effect of gas cavitation, which were improved in the full cavitation model proposed by Singhal et al. [26]. The full cavitation model accounts for the formation and transport of vapour bubbles, the turbulent fluctuations of pressure, and the magnitude of non-condensable gas. Li et al. [15] presented a new gas cavitation model based on air solubility in lubricant and the full cavitation model. The model is validated for fixed-geometry oil-film journal bearings at different eccentricity ratios. These results indicate the influence of gas cavitation on the elasticity modulus and the thermal effect of the gas-liquid mixture. However, it is still without the physical process and the exact identification of gas cavitation in fluid machinery.

As shown above, despite the gas and vapour cavitation both emerging in the low pressure region and take up the flow passage, their physical process are different [27]. The physical process of gas cavitation is the mass diffusion of dissolved air in oil and through interface. The physical process of vapour cavitation is the phase transition of vapour and liquid phase, and the process of phase transition is considerably quicker than mass diffusion process [28] and [29]. Furthermore, their effects on the performance of oil jet pumps are also different, which are used for the identification of gas cavitation in this study.

This study takes the gas cavitation in oil jet pumps for lubrication systems as its research subject. The gas cavitation was obtained with oil jet pumps operating under variable working conditions. The performance of oil jet pumps was systematically measured and quantified, and the performance curves of oil jet pumps under variable working conditions were obtained with experiments. Then, the frequency characteristics of cavitation and its action mechanism on the entrainment ability, efficiency, cavitation erosion ability, vibration, noise, vapour volume fraction of oil jet pumps were deeply and systematically analysed. Finally, a novel approach for the identification of gas cavitation and its effect on the performance of oil jet pumps were provided. 


\section{EXPERIMENTAL SETUP}

An experimental rig was constructed to simulate the environment of an oil jet pump in a lubrication system. Its schematic is shown in Fig. 2. The parameters of the oil jet pump are from a lubrication system in a power plant, with $m=7.47, t=65^{\circ} \mathrm{C}, P_{o}=2.6 \mathrm{MPa}, P_{c}$ in the range of $0.40 \mathrm{MPa}$ to $0.20 \mathrm{MPa}, h$ in the range of 0.08 to 0.2. Their expressions are shown in Eqs. (1) to (3). The volume fraction of dissolved air in lubrication oil is $7.2 \%$ at $65^{\circ} \mathrm{C}, 1 \mathrm{~atm}$ based on the study of Ding and Fan [13], equivalent to a mass fraction of $110 \mathrm{ppm}$.

The measured performance of the oil jet pump includes the entrainment ratio, efficiency, pressure distribution, cavitation erosion ability, vibration, and noise. Measurement points on the oil jet pump are shown in Fig. 3. Measurement ranges and accuracies of the experimental instruments are shown in Table 1. There are four PCB piezoelectric sensors arranged on the throat of the oil jet pump; their distances from the throat entrance are $0.5 D_{t}, 1 D_{t}, 1.5 D_{t}, 2.5$ $D_{t}$ respectively. Experimental results show that its maximum value emerges under variable working conditions. Thus, the maximum value among four points is taken as the representative parameter of oil jet pump. There are seven pressure transmitters arranged along flow direction, with distances of $0.5 D_{t}, 1 D_{t}$, $1.5 D_{t}, 2.5 D_{t}, 4 D_{t}, 5 D_{t}$ from the throat entrance respectively. Two vibration sensors are arranged on the throat and outlet pipe. A noise sensor is arranged outside the oil jet pump in a field $1 \mathrm{~m}$ distant. The measured dynamic parameters include cavitation

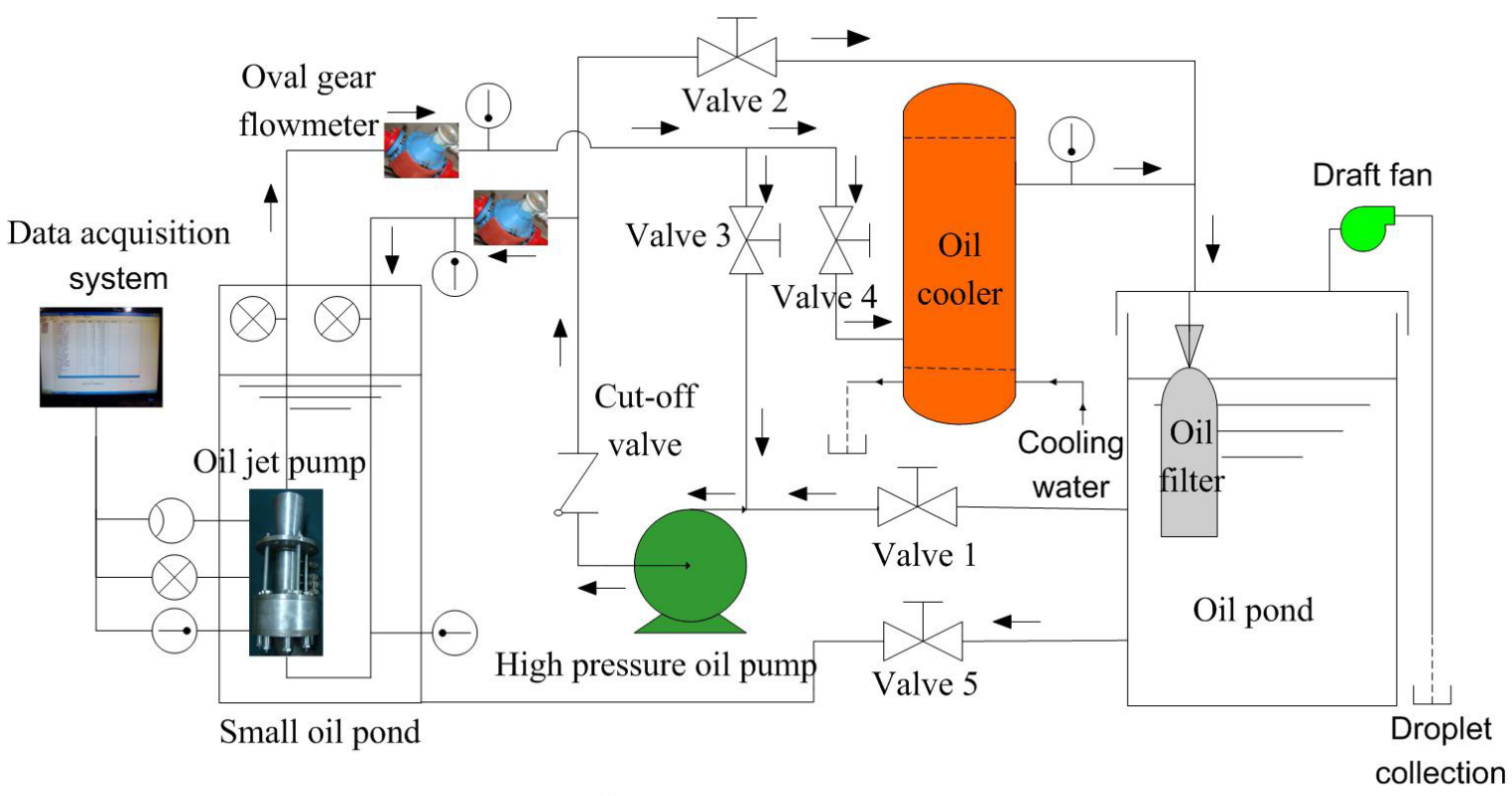

$\oslash$ Dynamic parameters sensor $\bigotimes$ - Static pressure transmitter $\Theta$-Thermocouple

Fig. 2. Schematic of experimental rig

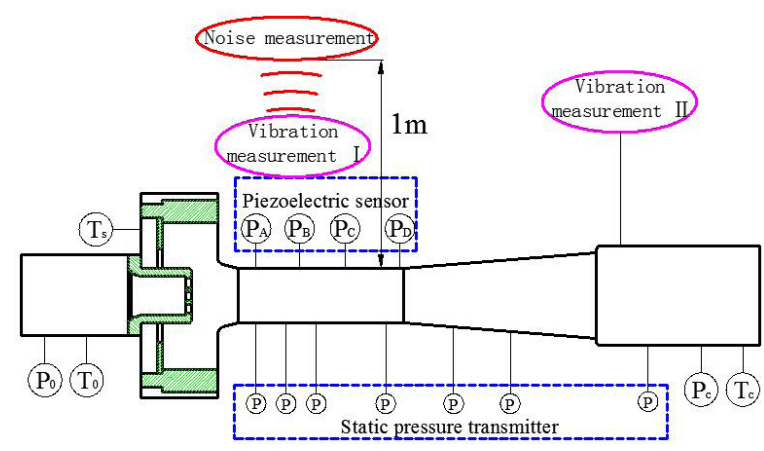

Fig. 3. Arrangement of measuring points on the oil jet pump erosion ability, vibration, noise, and their pictures are shown in Fig. 4.

Position along flow direction $L_{\mathrm{o}}=\frac{L}{D_{t}}$,

area ratio $m=\frac{F_{t}}{F_{o}}$,

pressure ratio $h=\frac{P_{c}-P_{s}}{P_{o}-P_{c}}$. 

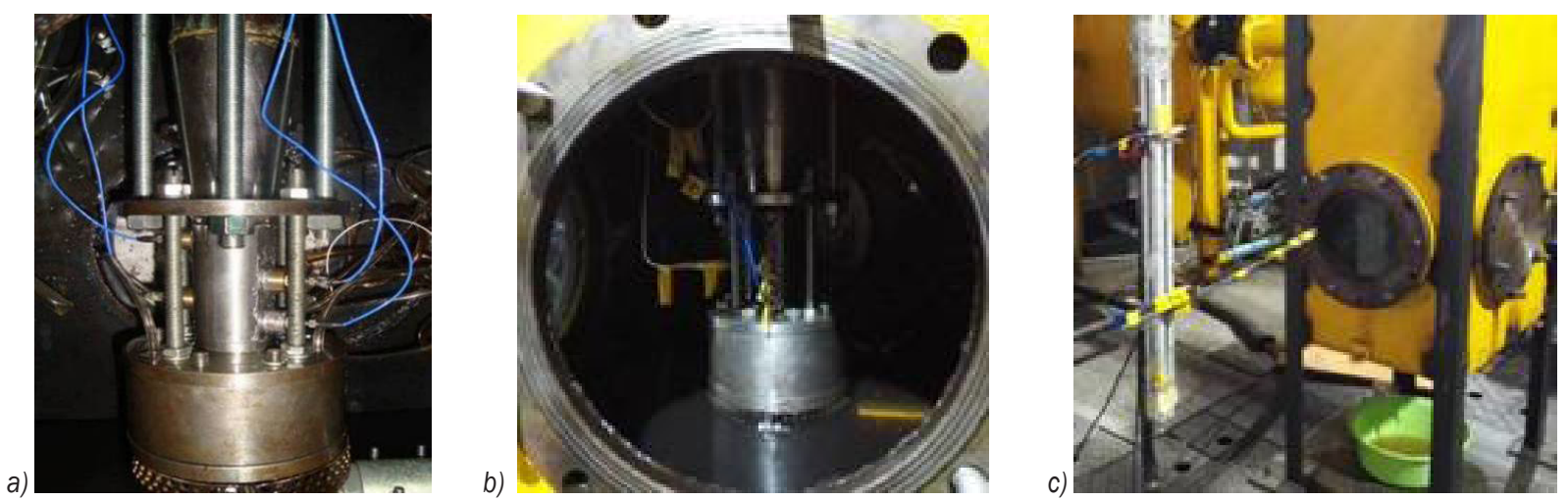

Fig. 4. Arrangement of dynamic parameter measurement points on the oil jet pump;

a) PCB piezoelectric sensor, b) vibration sensor, c) noise sensor

Table 1. Measurement ranges and accuracies of the experimental instruments

\begin{tabular}{lcc}
\hline $\begin{array}{l}\text { Measurement } \\
\text { parameter }\end{array}$ & Instrument & Range and accuracy \\
\hline Volume flow rate & Oval gear flow meter & $\begin{array}{c}10 \mathrm{~m}^{3} / \mathrm{h} \text { to } 60 \mathrm{~m} 3 / \mathrm{h}, \\
\pm 0.5 \%\end{array}$ \\
\hline Pressure & Rosemount high & $0 \mathrm{MPa}$ to $4 \mathrm{MPa}$, \\
& precision pressure & $\pm 0.1 \%$ \\
\hline transmitter & $-50^{\circ} \mathrm{C}$ to $350^{\circ} \mathrm{C}$, \\
Temperature & T type thermocouple & $0.4 \%$ \\
\hline Cavitation erosion & PCB piezoelectric sensor & $0 \mathrm{MPa}$ to $7 \mathrm{MPa}$, \\
ability & PCB acceleration sensor & $200 \mathrm{kHz}$ \\
\hline Vibration & PCB microphone & $200 \mathrm{kHz}$ \\
\hline Noise & & \\
\hline
\end{tabular}

\section{NUMERICAL SIMULATION METHOD}

The three-dimensional oil jet pump is filled with unstructured grids, as shown in Fig. 5. The grid number was initially 9.2 million and later increased to 14.7 million to ensure the grid independence of simulation results.

The Fluent commercial computational fluid dynamics (CFD) code was employed in the simulation. The averaged Reynolds number in the nozzle and throat zone is $3 \times 10^{6}$. Thus, the turbulence flow was solved with realizable k-epsilon model together with the standard wall functions. The $y+$ value on the boundaries is about 23 in the key flow area. The mixture model and full cavitation model developed by Singhal et al. [26] were employed to account for the effect of dissolved air in the lubrication oil.

Fig. 6 shows the boundary conditions of oil jet pump. Pressure boundary conditions were applied to the inlets and outlet boundaries. Each boundary was extended by 3 times of its pipe diameter. The boundaries were supplied with turbulence intensity of $5 \%$ and the hydraulic diameter of each pipe to eliminate the effect of backflow and ensure inflow condition. The SIMPLEC was employed to couple the pressure and velocity. The second order upwind was used for the discretization of convection terms. The solution was iterated until the residues for each equation were below $1 \times 10^{-4}$, and the net flux of inlets and outlet boundaries fluctuates in $1 \%$. Later, the simulation results were validated with experimental data; the relative error does not exceed $4 \%$.

Typically, about $24 \mathrm{~h}$ were needed to obtain a converged result for one case, which was calculated on a DELL Workstation (Intel(R) Xeon(R) Gold 5118 Processor@2.3 GHz (12 CPUs), DDR4 32G Running Memory).

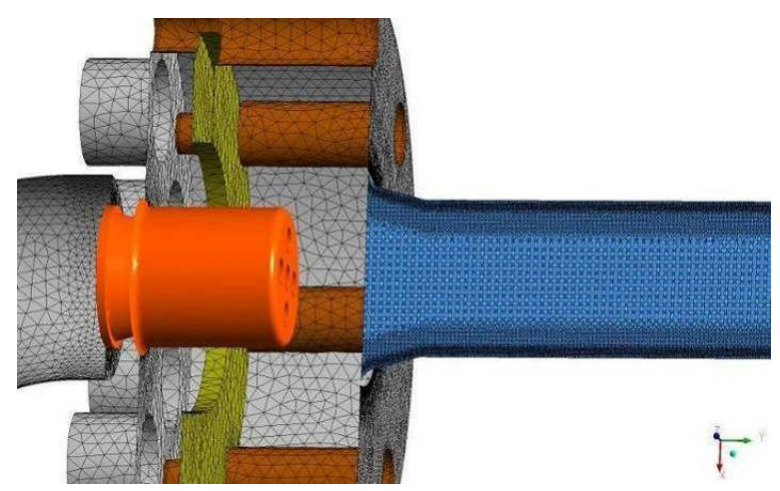

Fig. 5. Calculation domain and grids of oil jet pump

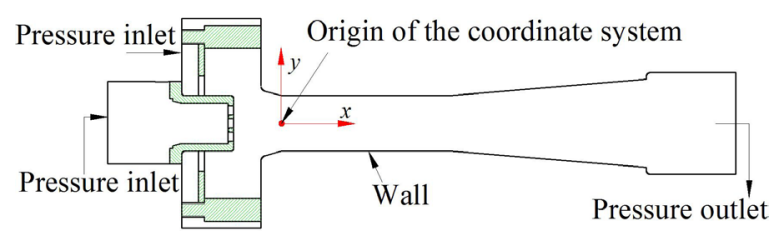

Fig. 6. Boundary conditions of oil jet pump 


\section{QUANTIFICATION OF THE DYNAMIC PARAMETERS}

The measured performance of the oil jet pump includes entrainment, efficiency, cavitation erosion ability, vibration, and noise. In these parameters, the entrainment, efficiency and cavitation erosion ability are quantified with entrainment ratio $q$, efficiency $\eta$, cavitation intensity $E$ [30]. Their expressions are shown in Eqs. (4) to (6). The quantification of vibration and noise are relatively complicated, because the effective experimental data are affected by the background such as motor of oil pump, pipe, valve, and elbow. In this study, the interfering signal was removed through the frequency characteristics of the cavitation process.

Entrainment ratio $\quad q=\frac{Q_{s}}{Q_{o}}$,

efficiency $\quad \eta=\frac{Q_{s}\left(P_{c}-P_{s}\right)}{Q_{o}\left(P_{o}-P_{c}\right)}=q \cdot h$,

cavitation intensity $\quad E=\frac{1}{T_{\text {sample }}} \cdot \frac{1}{\rho c} \sum_{i=1}^{n} P_{i}^{2} \Delta T_{i}$.

\subsection{Wavelet Analysis of Signal from PCB Piezoelectric Sensor}

The PCB piezoelectric sensor is arranged on the internal pipe wall close to flow, which is able to catch the original signal of cavitation process, as shown in Fig. 7. The frequency characteristics were obtained with the spectral analysis method. However, the conventional Fourier change is no longer suitable for the unilateral signal, which results from bubble collapse and its effect on the wall. Therefore, the wavelet analysis was adopted in this study. A single peak from Fig. 7 was chosen as the analysis object, which is typical and relatively independent of the other peaks. The Mexican Hat function was chosen as wavelet basis function based on its waveform in Fig. 7.

The time domain of single peak and its wavelet analysis results are shown in Fig. 8. The time period of peak emerges in wavelet analysis results corresponding to that in its time domain. Its dominant frequency distributes in the middle and high frequencies, which is concordant with the other pulses in Fig. 7. Fig. 9 shows the frequency distribution of the wavelet analysis result with different pressure ratios. The amplitude of the wavelet analysis goes up with increasing pressure ratio. Their frequency mainly distributes in the range of $5 \mathrm{kHz}$ to $85 \mathrm{kHz}$, and its peak emerges at $30 \mathrm{kHz}$.

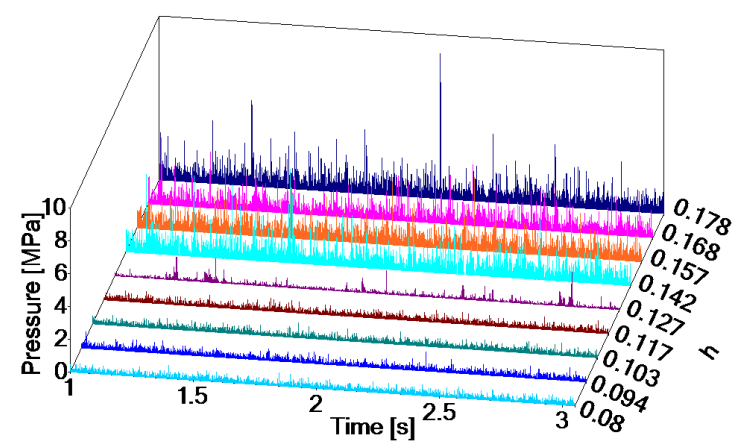

Fig. 7. Signal from PCB piezoelectric sensors with different pressure ratios

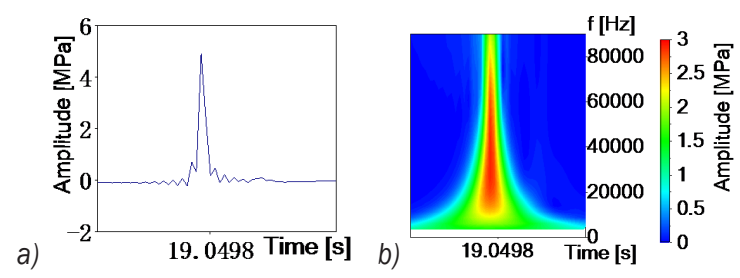

Fig. 8. Time domain of single peak and its wavelet analysis results: a) time domain, b) wavelet analysis results

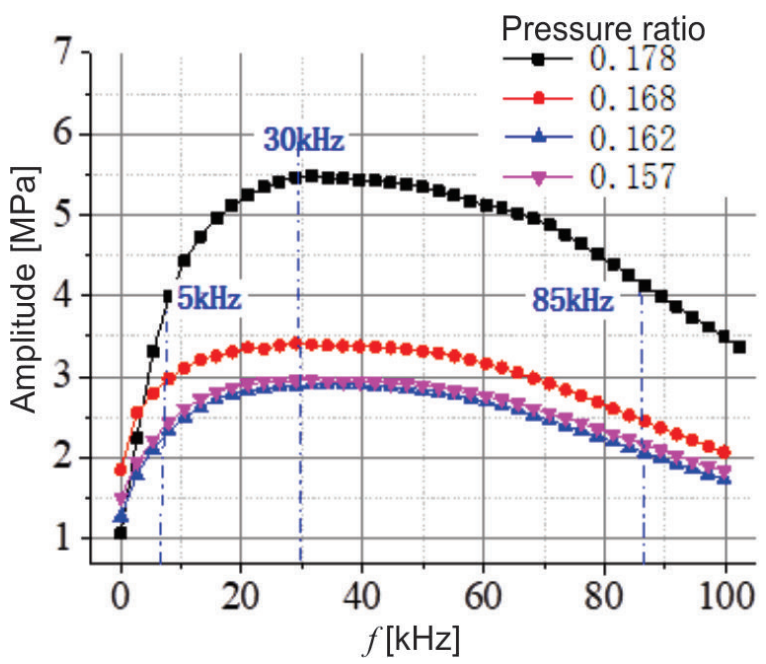

Fig. 9. Frequency distribution of wavelet analysis result with different pressure ratios

\subsection{Quantification of Cavitation Noise}

Fig. 10 shows the 1/12 octave band of sound signal under different working conditions. With the increase of the pressure ratio, the low frequency parts change a little, while their mainly difference appears in the middle and high frequency range with $f>5 \mathrm{kHz}$. It is obviously that these results are coincident with the 
wavelet analysis results. It is shown that the noise of cavitation process is based on the single pole sound source radiation noise with wide frequency characteristics, and is mainly distributed in the middle and high frequency ranges with $f>5 \mathrm{kHz}$. As a result, this study takes $5 \mathrm{kHz}$ to $20 \mathrm{kHz}$ as the cavitation noise frequency range, and its corresponding sound pressure level is taken as the quantitative parameter of cavitation noise.

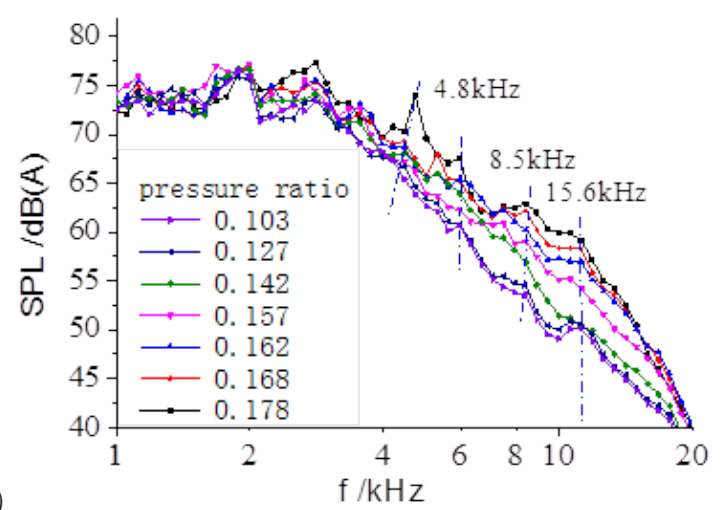

a)

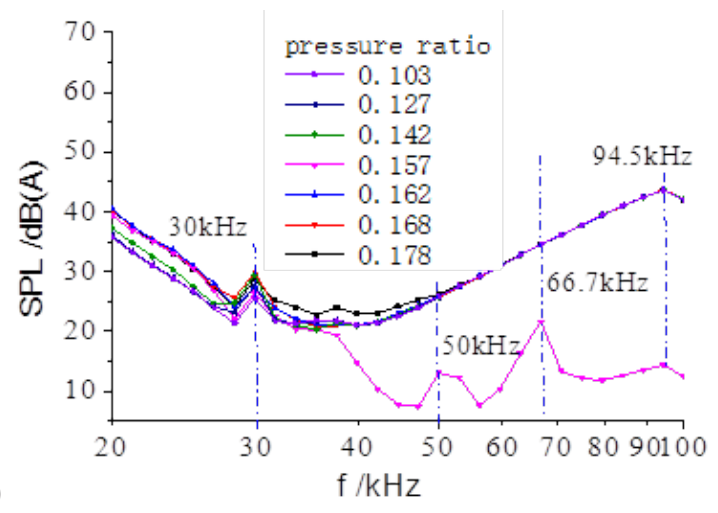

Fig. 10. Octave of sound signal with different pressure ratios;

a) $f<20 \mathrm{kHz}$, and b) $f>20 \mathrm{kHz}$

\subsection{Quantification of Cavitation Vibration}

In our experiment, there are elastic connections arranged at the inlet and outlet pipes of oil jet pump to isolate the vibration of attachments. Thus, the quantification of cavitation vibration is relatively simple. Fig. 11 shows the acceleration of throat vibration under different working conditions. It is obvious that the peak-to-peak value of vibration acceleration increases rapidly with the increase of pressure ratio. As a result, the P-P value of vibration acceleration is taken as the quantitative parameter of cavitation vibration.

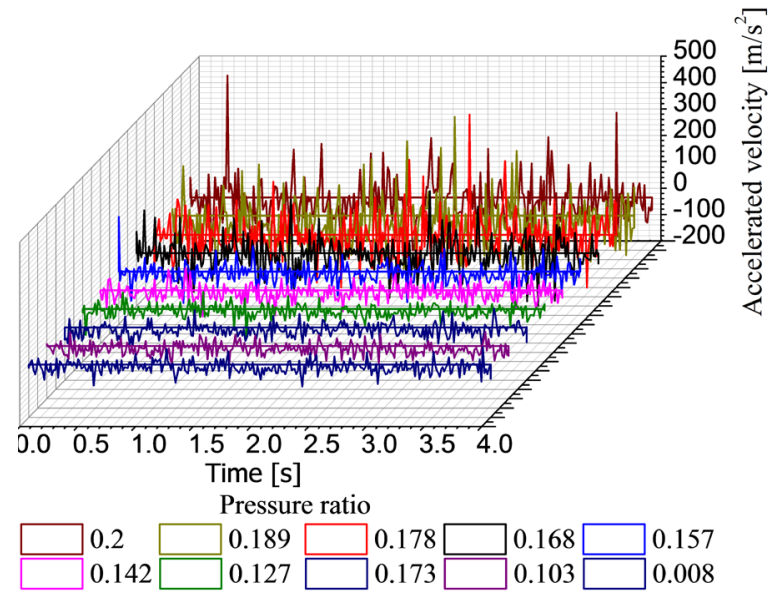

Fig. 11. Acceleration of throat vibration with different pressure ratios

\section{RESULTS}

\subsection{Numerical Simulation Results}

Figs. 12 and 13 show the distribution of vapour volume fraction in the oil jet pump from numerical simulation. In the pressure ratio range from 0.155 to 0.144 , the oil jet pump mainly suffers from gas cavitation. In this range, the pressure in throat decreases with decreasing $\mathrm{h}$ and more air separates from lubrication oil. As shown in Fig. 12, the gas cavitation zone remains almost unchanged, and its volume fraction gradually increases with decreasing $h$.

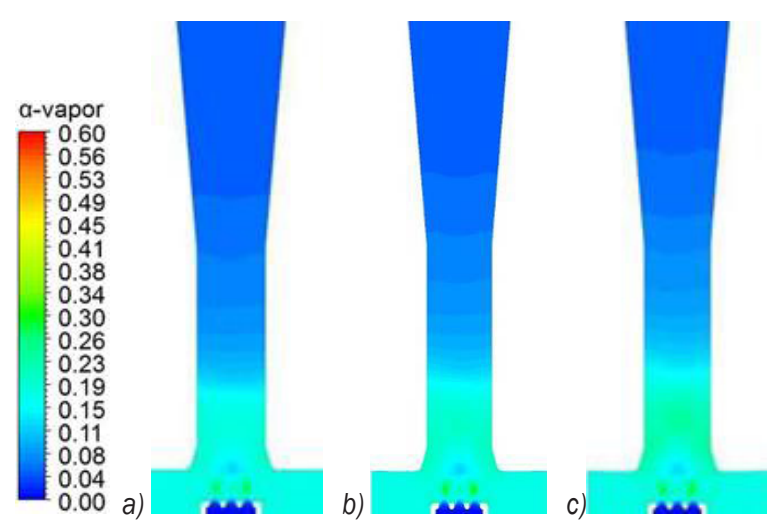

Fig. 12. Vapour volume fraction in oil jet pump with different pressure ratios (gas cavitation);

a) $h=0.155$, b) $h=0.15$, c) $h=0.144$

In the pressure ratio range of 0.102 to 0.139 , the oil jet pump mainly suffers from vapour cavitation. In this range, the decreasing low pressure inertia is blocked by the phase change of lubrication oil, and evolves to the increasing phase change region in 

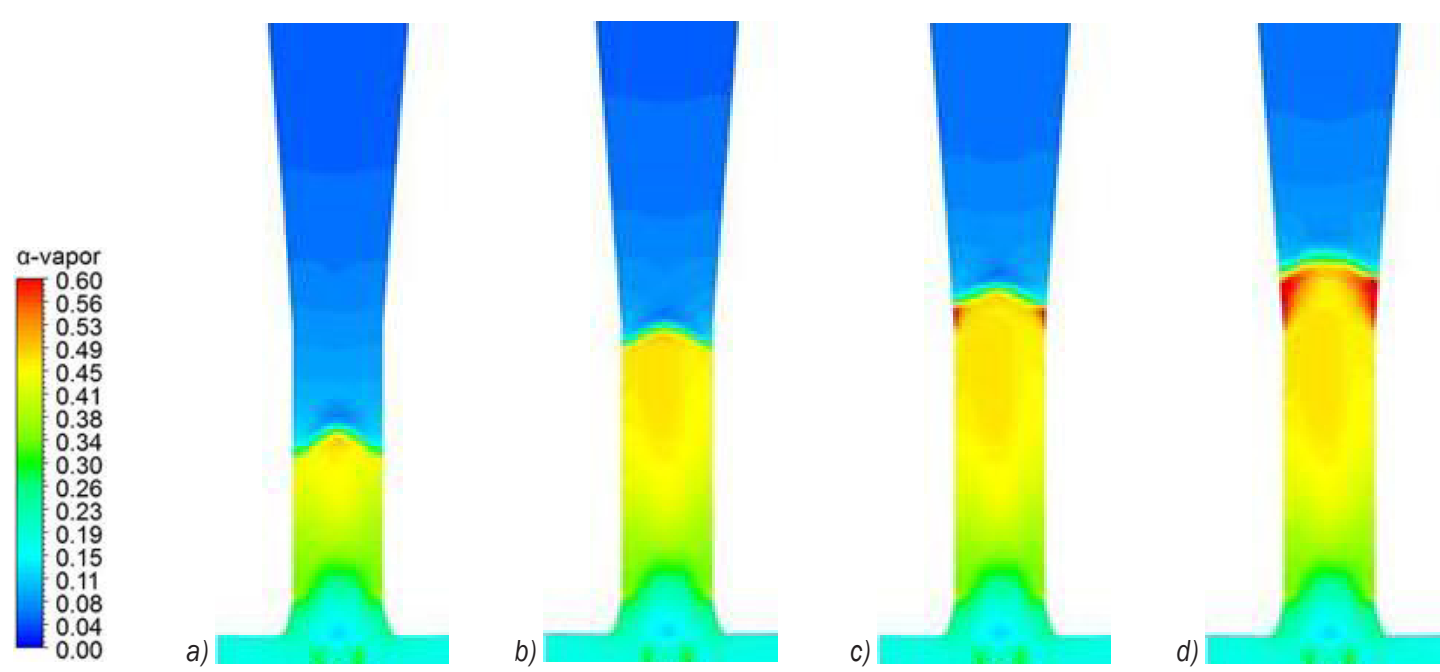

Fig. 13. Vapour volume fraction in oil jet pump with different pressure ratios (vapour cavitation):

a) $h=0.139$, b) $h=0.128$, c) $h=0.113$, d) $h=0.102$

throat. Therefore, the vapour cavitation zone extends downstream until throat is full of cavitation bubbles; the vapour volume fraction also increases with decreasing $h$, as shown in Fig. 13.

\subsection{Experimental Results}

Fig. 14 shows the entrainment ratio $q$, efficiency $\eta$, cavitation intensity $E, 5 \mathrm{kHz}$ to $20 \mathrm{kHz}$ sound pressure level $S P L$, throat vibration P-P TPP, outlet vibration P-P $O P P$ change with pressure ratio $h$ from experimental results. Combined with numerical simulation results in Figs. 12 and 13, more details and results were obtained.

(1) Entrainment ratio, $q$ : Due to the emergence of gas cavitation in the throat pipe, the entrainment ratio gradually increases to its maximum with decreasing pressure ratio, and the oil jet pump enters choking flow.

(2) Efficiency, $\eta$ : The efficiency curve shows a parabolic shape. Its maximum point corresponds to the critical point of non-choking transforming choking flow with $h=0.155$, which is also affected by gas cavitation.

(3) Cavitation intensity, E: The cavitation intensity shows a rising trend with increasing pressure ratio, and there is a local minimum point with $h$ $=0.155$. These data suggest that moderate gas cavitation is able to decrease cavitation intensity in oil jet pump. More explanation can be found in a previous study [30].

(4) Throat vibration P-P, TPP: Since the PCB piezoelectric sensor and vibration sensor were arranged on the inside and outside of throat wall, the throat vibration has a similar change rule with cavitation intensity. However, the pressure ratio of local maximum points varies because of their different formation mechanisms. The local maximum point of throat vibration emerges at the point of non-choking transforming choking flow. During the transformation, the air dissolves from the oil, and the gas-liquid flow leads to the compressibility of the mixture, which leads to the vibration of throat. The local maximum point of cavitation intensity results from the concentrated collapse of cavitation bubbles under choking flow [30].

(5) $5 \mathrm{kHz}$ to $20 \mathrm{kHz}$ sound pressure level, SPL: Compared to the throat vibration, the high frequency noise is absent from the local maximum point. That is because, even though the gas cavitation leads to the compressibility of mixture, the dissolution and precipitation process of air are relatively slow compared to the phase change process of the lubrication oil. Therefore, gas cavitation has little effect on high frequency noise, and the $S P L$ curve is void of the local maximum point.

(6) Outlet vibration P-P, OPP: The outlet vibration curve shows a bowl shape, which is symmetric with efficiency curve. These data shows that gas cavitation has little effect on outlet vibration because it emerges at the upstream part of the throat pipe. 


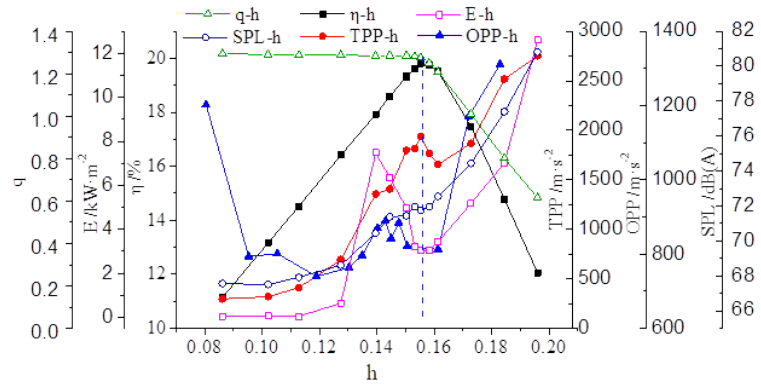

Fig. 14. Cavitation characteristics of oil jet pump from experimental results

\section{DISCUSSION}

In this paper, it is shown that gas cavitation can be identified by its physical process and effect on the performance of oil jet pumps under variable working conditions. It is evident that gas cavitation emerges at the low pressure region of throat pipe, and its primary effect is the transformation from non-choking to choking flow in oil jet pump. This effect is important but is often neglected due to the small amount of dissolved air in water jet pump. However, gas cavitation cannot be neglected for lubrication oil in oil jet pumps. Our study serves for the identification of gas cavitation and analyses in depth its effect on the performance of oil jet pumps.

One important innovation of our study is providing an approach for identifying gas cavitation in oil jet pumps. Compared with vapour cavitation, gas cavitation cannot induce high frequency noise because the generation and collapse process of gas cavitation were limited by the dissolution and precipitation velocity of the dissolved air from lubrication oil. However, gas cavitation produces liquid-gas mixed flow and intensify the vibration. Thus, the gas cavitation is identified by comparison of vibration and high frequency noise under variable working conditions.

Furthermore, our study deeply analysed the effect of gas cavitation on the performance of oil jet pumps based on systematically experimental results. Fig. 15 shows the pressure distribution in oil jet pump from experiment. The cavitation number is obtained with Eq. (7). $P_{a}$ is the pressure at the beginning of throat pipe, $P_{v}$ is the vaporization pressure of lubrication oil. Then the critical points of gas cavitation in oil jet pump were obtained, as shown in Table 2 .

Cavitation number: $\quad \sigma=\frac{P_{s}-P_{v}}{\rho v_{s}^{2} / 2}=\frac{P_{s}-P_{v}}{P_{s}-P_{a}}$.

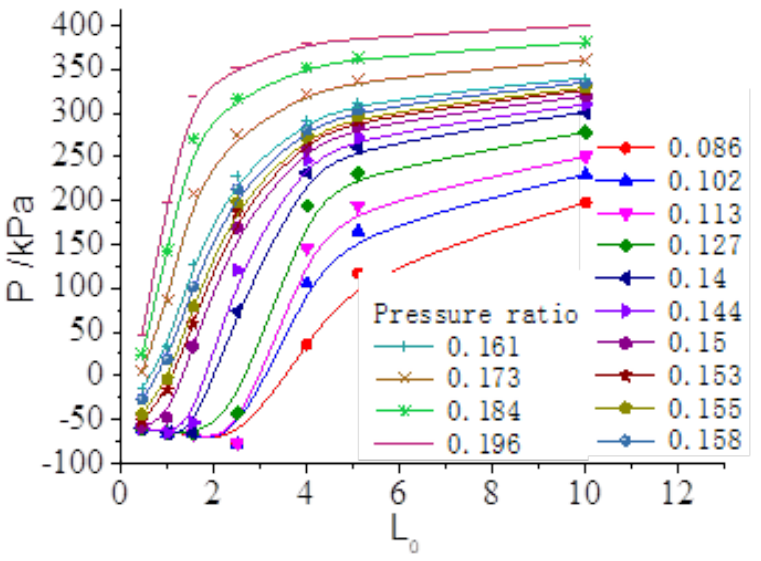

Fig. 15. Pressure distribution in oil jet pump from experiment

Table 2. Critical points of gas cavitation

\begin{tabular}{lccc}
\hline Critical point & $h=0.144$ & $h=0.155$ & $h=0.161$ \\
\hline$\sigma$ & 1.31 & 1.54 & 1.68 \\
\hline$Q$ & 1.29 & 1.28 & 1.21 \\
\hline$\eta[\%]$ & 18.58 & 19.8 & 19.5 \\
\hline$E\left[\mathrm{~W} \cdot \mathrm{kg}^{-1}\right]$ & 6.34 & 3.03 & 3.46 \\
\hline$T P P\left[\mathrm{~m} \cdot \mathrm{s}^{-2}\right]$ & 1405.3 & 1937.37 & 1655.5 \\
\hline$O P P\left[\mathrm{~m} \cdot \mathrm{s}^{-2}\right]$ & 796.4 & 841.65 & 821.8 \\
\hline$S P L[\mathrm{~dB}(\mathrm{~A})]$ & 71.4 & 71.74 & 72.6 \\
\hline
\end{tabular}

From the above, we have identified the dimensionless range of gas cavitation. Gas cavitation emerges in the range of $0.144<h<0.161$, with $1.31<\sigma<1.68$ in this study. These data mean the gas cavitation inception emerges at $h=0.161$ with $\sigma=1.68$ and fades away at $h=0.144$ with $\sigma=1.31$.

Our results confirm and provide quantitative data for the effect of dissolved air on cavitation in oil jet pumps. In this study, the dissolved air content in lubrication oil $f_{g}=110 \mathrm{ppm}$, and the limited cavitation number of oil jet pump $\sigma_{L}=1.54$, compared to $\sigma_{L}=1.33$ in water jet pump with $f_{g}=15 \mathrm{ppm}$ from Cunningham and Brown [17], the dissolved air content is 6.3 times larger, and the oil jet pump is more prone to suffer from cavitation than water jet pump by $16 \%$.

Our results suggest a possibility of reducing cavitation erosion with moderate gas cavitation in oil jet pumps. The local minimum cavitation intensity point result from gas cavitation is also the high efficiency point with $h=0.155$ and $\sigma=1.54$. Its cavitation number is $10 \%$ lower than gas cavitation inception, while its throat vibration P-P value is $17 \%$ higher. Additionally, the maximum entrainment ability of oil jet pumps is $6.6 \%$ higher than that of the gas cavitation inception point. 


\section{CONCLUSION}

In this study, a novel approach for identifying gas cavitation in oil jet pumps is provided. Such an approach accounts for the physical process of gas cavitation and its effect on oil jet pumps, which is of great significance for engineering.

The gas cavitation and its effect on the performance of oil jet pumps under variable working conditions are systematically measured and quantified with the entrainment ratio, efficiency, cavitation intensity, $5 \mathrm{kHz}$ to $20 \mathrm{kHz}$ sound pressure level, and vibration P-P value. Additionally, the vapour volume fraction and pressure distribution were obtained to provide more details of gas cavitation in oil jet pumps. Finally, the results of gas cavitation affecting the performance of oil jet pumps are obtained. The main conclusions are as follows:

(1) A novel approach for identifying gas cavitation in oil jet pumps is provided with comparison of vibration and high frequency noise under variable working conditions.

(2) In this study, the dissolved air content in lubrication oil $f_{g}=110 \mathrm{ppm}$ and gas cavitation emerges in the range of $0.144<h<0.161$, with gas cavitation emerging at $\sigma=1.68$ and fading away at $\sigma=1.31$.

(3) The dissolved air content in lubrication oil is 6.3 times larger than that in water. Furthermore, the oil jet pump is more prone to suffer from cavitation than a water jet pump by $16 \%$.

\section{ACKNOWLEDGEMENTS}

This work was financially supported by the Fundamental Research Funds for the Central Universities (JZ2017HGBZ0946) and Major Scientific and Technological Projects in Anhui Province (JZ2017AKKZ1176).

\section{NOMENCLATURES}

$D$ diameter, [m]

$L$ length, [m]

$F$ area, $\left[\mathrm{m}^{2}\right]$

$P$ pressure (gauge pressure), [MPa]

$T$ time, [s]

$Q \quad$ flow rate, $\left[\mathrm{m}^{3} \mathrm{~h}^{-1}\right]$

$f_{g}$ mass fraction of dissolved air, [ppm]

$\sigma$ cavitation number, [-]

subscripts

$t$ throat, $o$ working oil flow,

$s$ suction oil flow,

$c$ outlet oil flow,

$i$ dynamic parameter,

$v$ lubrication oil vapour,

$a$ beginning of throat pipe.

\section{REFERENCES}

[1] Lin, Q., Bao, Q., Li, K., Khonsari, M.M, Zhao, H. (2018). An investigation into the transient behavior of journal bearing with surface texture based on fluid-structure interaction approach. Tribology International, vol. 118, p. 246-255, D0l:10.1016/j. triboint.2017.09.026.

[2] Meng, F.M., Zhang, L., Long, T. (2016). Effect of groove textures on the performances of gaseous bubble in the lubricant of journal bearing. Journal of Tribology, vol. 139, no. 3, p. 31701, DOI:10.1115/1.4034247.

[3] Morgut, M., Jošt, D., Škerlavaj, A., Nobile, E., Contento, G. (2018). Numerical predictions of cavitating flow around a marine propeller and Kaplan turbine runner with calibrated cavitation models. Strojniški vestnik - Journal of Mechanical Engineering, vol. 64, no. 9, p. 543-555, D0l:10.5545/svjme.2017.4647.

[4] Garg, N, Pearce, B.W, Brandner, P.A, Phillips, A.W., Martins, J.R.R.A., Young, Y.L. (2019). Experimental investigation of a hydrofoil designed via hydrostructural optimization. Journal of Fluids and Structures, vol. 84, p. 243-262, D0I:10.1016/j. jfluidstructs.2018.10.010.

[5] Wu, Q., Huang, B., Wang, G., Cao, S. (2018). The transient characteristics of cloud cavitating flow over a flexible hydrofoil. International Journal of Multiphase Flow, vol. 99, p. 162-173, D0I:10.1016/j.ijmultiphaseflow.2017.10.006.

[6] Li, D., Kang, Y., Ding, X., Wang, X., Fang, Z. (2017). Effects of nozzle inner surface roughness on the performance of self-resonating cavitating waterjets under different ambient pressures. Strojniški vestnik - Journal of Mechanical Engineering, vol. 63, no. 2, p. 92-102, Dol:10.5545/svjme.2016.3563.

[7] Stepišnik Perdih, T., Širok, B., Dular, M. (2017). Influence of hydrodynamic cavitation on intensification of laundry aqueous detergent solution preparation. Strojniški vestnik Journal of Mechanical Engineering, vol. 63, no. 2, p. 83-91, DOl:10.5545/sv-jme.2016.3970.

[8] Biluš, I., Bombek, G., Hočevar, M., Širok, B., Cenčič, T., Petkovšek, M. (2014). The experimental analysis of cavitating structure fluctuations and pressure pulsations in the cavitation station. Strojniški vestnik - Journal of Mechanical Engineering, vol. 60, no. 3, p. 147-157, D0l:10.5545/svjme.2013.1462.

[9] Concli, F. (2016). Pressure distribution in small hydrodynamic journal bearings considering cavitation: A numerical approach based on the open-source CFD code OpenFOAM ${ }^{\circledR}$. Lubrication Science, vol. 28, no. 6, p. 329-347, D0l:10.1002/Is.1334.

[10] Chauhan, A., Singla, A., Panwar, N., Jindal, P. (2014). CFD based thermo-hydrodynamic analysis of circular journal bearing. International Journal of Advanced Mechanical Engineering, vol. 4, no. 5, p. 475-482. 
[11] Zhang, X., Wang, D., Liao, R., Zhao, H., Shi, B. (2018). Study of mechanical choked Venturi nozzles used for liquid flow controlling. Flow Measurement and Instrumentation, vol. 65, p. 158-165, D0I:10.1016/J.flowmeasinst.2018.12.001.

[12] Singh, S., Choi, J.-K., Chahine, G.L. (2013). Characterization of cavitation fields from measured pressure signals of cavitating jets and ultrasonic horns. Journal of Fluids Engineering, vol. 135, no. 9, p. 91302, Dol:10.1115/1.4024263.

[13] Ding, C., Fan, Y.R. (2011). Measurement of diffusion coefficients of air in silicone oil and in hydraulic oil. Chinese Journal of Chemical Engineering, vol. 19, no. 2, p. 205-211, DOI:10.1016/s1004-9541(11)60155-9.

[14] Nüllig, M., Peters, F. (2018). Experiments on the mass transfer of gas bubbles in mineral oil. Colloids and Surfaces $A$ : Physicochemical and Engineering Aspects, vol. 540, p. 81-89, DOI:10.1016/j.colsurfa.2017.12.057.

[15] Li, X.-S, Song, Y, Hao, Z.-R., Gu, C.-W. (2012). Cavitation mechanism of oil-film bearing and development of a new gaseous cavitation model based on air solubility. Journal of Tribology, vol. 134, no. 0317013, p. 31701-31707, DOl:10.1115/1.4006702.

[16] Zhou, J., Hu, J., Jing, C. (2016). Lumped parameter modelling of cavitating orifice flow in hydraulic systems. Strojniški vestnik - Journal of Mechanical Engineering, vol. 62, no. 6, p. 373380, DOl:10.5545/sv-jme.2015.3082.

[17] Cunningham, R.G, Brown, F.B. (1970). Oil jet pump cavitation. ASME Cavitation Forum, Detroit.

[18] Long, X., Yao, H., Zhao, J. (2009). Investigation on mechanism of critical cavitating flow in liquid jet pumps under operating limits. International Journal of Heat and Mass Transfer, vol. 52, no. 9-10, p. 2415-2420, D0l:10.1016/j. ijheatmasstransfer.2008.11.018.

[19] Zhang, J., Mao, J.R., Wang, S.S., Zhang, J.J, Sun, P. (2015). Influence of noncondensible gas on flowing characteristics of multiple nozzle oil jet pump for lubrication system in steam turbine. Proceedings of the Institution of Mechanical Engineers, Part A: Journal of Power and Energy, vol. 229, no. 8, p. 876-888, Dol:10.1177/0957650915593025.

[20] Zou, J., Fu, X., Du, X.W., Ruan, X.D,, Ji. H., Ryu, S., Ochiai, M. (2008). Cavitation in a non-circular opening spool valve with U-grooves. Proceedings of the Institution of Mechanical Engineers, Part A: Journal of Power and Energy, vol. 222, no. 4, p. 413-420, DOl:10.1243/09576509JPE489.
[21] Duke, D.J., Kastengren, A.L., Swantek, A.B., Matusik, K.E., Powell, C.F. (2016). X-ray fluorescence measurements of dissolved gas and cavitation. Experiments in Fluids, vol. 57, no. 10, p. 162, Dol:10.1007/s00348-016-2250-5.

[22] Kim, S., Murrenhoff, H. (2012). Measurement of effective bulk modulus for hydraulic oil at low pressure. Journal of Fluids Engineering, vol. 134, no. 2, p. 021201 , DOl:10.1115/1.4005672.

[23] Zhou, J., Wei, C., Hu, J. (2015). A novel approach for predicting thermal effects of gas cavitation in hydraulic circuits. Energy, vol. 83, p. 576-582, D0I:10.1016/j.energy.2015.02.065.

[24] Kunz, R.F., Boger, D.A., Stinebring, D.R., Chyczewski, T.S., Lindau, J.W., Gibeling, H.J., Venkateswaran, S., Govindan, T.R. (2000). A preconditioned Navier-Stokes method for two-phase flows with application to cavitation prediction. Computers and Fluids, vol. 29, no. 8, p. 849-875, D0l:10.1016/S00457930(99)00039-0.

[25] Sauer, J. (2000). Instationaren Kaviterende StromungEin neues Modell, basierend auf Front Capturing (VoF) and Blasendynamik. PhD Thesis, University of Karlsruhe, Karlsruhe.

[26] Singhal, A.K., Athavale, M.M., Li, H.Y., Jiang, Y. (2002). Mathematical basis and validation of the full cavitation model. Journal of Fluids Engineering, vol. 124, no. 3, p. 617-624, DOl:10.1115/1.1486223.

[27] Prosperetti, A. (2017). Vapor bubbles. Annual Review of Fluid Mechanics, vol. 49, no. 1, p. 221-248, D0l:10.1146/annurevfluid-010816-060221.

[28] Kratschun, F., Mielke, T., Schmitz, K. (2018). Water vapour cavitation in hydraulic fluids. 2018 Symposium on Fluid Power and Motion Control, Bath, p. V001T01A038, D0l:10.1115/ FPMC2018-8872.

[29] Krahl, D., Weber, J., Fuchs, M. (2016). Visualization of cavitation and investigation of cavitation erosion in a valve. 10th International Fluid Power Conference, Dresden, p. 333347.

[30] Zhang, J., Mao, J., Wang, S., Wu, B., Yuan, H., Wang, K., Zhang, J., Sun, P. (2014). Experimental study on the cavitation characteristics of an oil jet pump with multiple nozzles for the lubrication system in a steam turbine. Journal of Engineering for Gas Turbines and Power, vol. 136, no. 12, p. 122605 , DOI:10.1115/1.4027832. 